\title{
Attentional limitations in processing sequentially presented vibrotactile targets
}

\author{
ANNE P. HILLSTROM \\ University of Texas, Arlington, Texas \\ KIMRON L. SHAPIRO \\ University of Wales, Bangor, Wales \\ and \\ CHARLES SPENCE \\ Oxford University, Oxford, England
}

\begin{abstract}
In seven experiments, participants experienced rapid, serially presented streams of vibrations and responded to specific targets in the streams. In visual (and sometimes auditory) streams presented in this manner, it is typical to find a deficit in reporting the second of two targets when both must be reported and the second appears within a short temporal interval of the first, but not when identical displays are presented but only the second target must be reported (e.g., the attentional blink, or AB). This conventional AB pattern was found in the last experiment, in which judgments were about targetlocation. However in the first six experiments reported here, in which judgments were about frequency, intensity, duration, or location of targets, accuracy was dependent on target separation regardless of whether or not the first target was reported. This unconventional pattern could represent an $\mathrm{AB}$ if the first target was attended even when it was not reported. The evidence for this claim and an alternative possibility that location judgments are especially sensitive to attention manipulations are discussed.
\end{abstract}

Selecting a sensory stimulus to process from many available stimuli is a keystone to voluntary behavior. Such selection is what most people think of as attention. Much of the research about selection has focused on intramodal selection within the visual or auditory modalities. Research about selective attention to tactile, olfactory, and gustatory stimuli is far less common (though see Marks \& Wheeler, 1998; Spence, Kettenmann, Kobal, \& McGlone, 2000). In the present study, we investigated the selection of tactile stimuli.

The need for and existence of selective attention has been demonstrated for tactile stimuli. When observers search through tactile stimuli presented one to a fingertip, they can find targets that differ in terms of a single feature, such as temperature, orientation, texture, or hardness (Lederman \& Klatzky, 1997). Search is often effortful in these cases, which suggests that either overt orienting of subcutaneous receptors or covert direction of attention is needed in order to identify the individual stimuli. When

This research was supported in part by funding from the Wellcome Trust. The authors thank John Duncan, Louise Howard, Glyn Humphreys, Chris Rorden, and Salvador Soto-Faraco for helpful discussions of this work. Thanks also to Jeremy Howell, Frances Kellie, and Brian Norris for support in the lab and to Douglas Coyne and Pete Townshend for technical support. Correspondence should be addressed to A. P. Hillstrom, Department of Psychology, University of Texas, Arlington, TX 76019-0528(e-mail: hillstrom@uta.edu). one is trying to judge the direction of motion of a tactile target, the presence of moving distractors on adjacent fingers or on the other hand cannot be completely ignored (Evans \& Craig, 1991). But moving the hands farther apart usually reduces this interference (Driver \& Grossenbacher, 1996). A tactile cue to the location of the target does not facilitate search for a simple change in texture or change in vibration but can facilitate search when searching for a constant vibration or texture among distractors that do change (Sathian \& Burton, 1991; Whang, Burton, \& Shulman, 1991). In fact, a location cue speeds processing even when the target appears in isolation, when selection is not needed to discriminate targets from distractors (Bradshaw, Howard, Pierson, Phillips, \& Bradshaw, 1992; Butter, Buchtel, \& Santucci, 1989; Hsiao, O'Shaughnessy, \& Johnson, 1993; Post \& Chapman, 1991; Spence \& McGlone, 2001; Spence, Nicholls, Gillespie, \& Driver, 1998; Spence, Pavani, \& Driver, 2000; Zompa \& Chapman, 1995).

All of the research on tactile selection has explored selection among concurrent stimuli, whereas the work reported here explored selection among stimuli presented over time, in rapid succession. Selection from among sequentially presented visual streams of stimuli has been studied extensively (e.g., Broadbent \& Broadbent, 1987; Weichselgartner \& Sperling, 1987). In recent years, one focus of such research is how people select more than one target in serially presented visual streams. When peo- 
ple are asked to find two targets in a rapidly and serially presented visual stream, accuracy at reporting the second target is typically low when it closely follows the first target (i.e., 100-400 msec later), but not when the targets are farther apart in the stream (see Giesbrecht \& Di Lollo, 1998, and Shapiro, Arnell, \& Raymond, 1997, for recent reviews). When observers are shown the same stream of objects but are asked to report only the second of the two targets, accuracy at reporting the second target is typically unaffected by the relative positions of the two targets, as long as the definition of the second target is independent of the definition of the first (e.g., first target is a white letter, second is a black X). This phenomenon, which has proven to be robust when the targets are visual, has been labeled the attentional blink (AB; Raymond, Shapiro, \& Arnell, 1992).

Recently, there has been interest in determining whether the $A B$ is specific to the visual modality or else is due to more central limitations in processing sequential stimuli (Arnell \& Jolicœur, 1999; Duncan, Martens, \& Ward, 1997; Potter, Chun, Banks, \& Muckenhoupt, 1998). To date, the results suggest that the $\mathrm{AB}$ is found less reliably when the targets and nontargets in the stream are auditory rather than visual, or when one target is visual and the other is auditory, in a multimodal stream. An AB is sometimes found when two auditory targets are presented (Arnell \& Duncan, 1998; Arnell \& Jolicœur, 1999; Duncan et al., 1997; Goddard, Isaak, \& Slawinski, 1997, 1998; Mondor, 1998; Potter et al., 1998, Experiment 4; Shulman, 1994; Shulman \& Hsieh, 1995), but not always (Arnell \& Jolicœur, 1999; Potter et al., 1998, Experiments 1, 2, 5, and 6). When one auditory target and one visual target are presented, an AB is found under some conditions (Arnell \& Jolicœur, 1999; Potter et al., 1998, Experiment 4; Shulman \& Hsieh, 1995, Experiment 1) but not others (Duncan et al., 1997; Potter et al., 1998, Experiment 3 and 5; Shulman \& Hsieh, 1995, Experiment 2; Soto-Faraco \& Spence, 2002). In one study, an $A B$ was looked for and found when one target was visual and the other was tactile (Soto-Faraco et al., in press). Thus, there is evidence for both vision-specific and supramodal attentional limitations contributing to the $\mathrm{AB}$.

Potter et al. (1998) observed that the pattern of AB results could be summarized as follows: When at least one of the two targets to be reported is not visual, if the same selection criterion can be used to pick out both targets, then accuracy in reporting the second target is not affected by the time between the presentation of targets. But if different selection criteria are required to pick out the two targets, accuracy in reporting the second target is affected. This pattern of results is consistent with the presence of two types of limitation, one specific to vision and the other amodal. First, when both T1 and T2 are visual, the memory representation of visual items is not very durable, resulting in the representation of $\mathrm{T} 2$ being lost before attention can be directed to it. When the two targets to be reported are defined by different criteria, there is a more general limitation in the speed with which ob- servers can change task set, regardless of the modality of the stimuli.

There are at least three results that have proven exceptions to the claim that an $\mathrm{AB}$ will be found whenever either both targets are visual and masked or task set switching is needed between T1 and T2. In two of these experiments, different task sets were needed to select two different auditory targets, but there was no difference between the accuracies in dual-target report and single-target report (Arnell \& Jolicœur, 1999; Shulman \& Hsieh, 1995). Interestingly, there was an effect of stimulus onset asynchrony (SOA) between $\mathrm{T} 1$ and $\mathrm{T} 2$ in these experiments not only when participants reported $\mathrm{T} 1$ and $\mathrm{T} 2$ but also when participants reported only $\mathrm{T} 2$. Arnell and Jolicœur pointed out that this pattern of accuracies might reflect involuntary attention to T1 even when T1 is not reported, because of its perceptual distinctiveness. In the third exceptional situation, participants monitored two spatially separated streams (Duncan et al., 1997). They saw or heard three-letter syllable targets amid uniform nontarget syllables or letter strings. They did not know which stream would contain the first target, but the second target was always in the other stream. When the two streams were both auditory or both visual, an $\mathrm{AB}$ occurred; however, when one stream was auditory and the other visual, there was no AB. Potter et al. (1998) treated the auditory-auditory condition as the exceptional result, exceptional because they believed the task did not involve a task shift (in both cases, find distinctive syllables). They accounted for the exception as due to a problem of monitoring two auditory streams. But it is quite possible to interpret the experiment as requiring two different task sets because the target syllables in one stream were highly discriminable from the target syllables in the other streams. Under that interpretation, the exceptional result is that Duncan et al. (1997) found no crossmodal AB when task-set switching should have been involved.

The theorizing about the $\mathrm{AB}$ has so far been based on primarily two sensory modalities, vision and audition. In order to determine the degree to which the $\mathrm{AB}$ reflects a truly supramodal limitation on information processing, it is important to observe the nature of attentional switching in other sensory modalities as well. We therefore sought to determine whether an $\mathrm{AB}$ would be observed when searching for targets in streams of vibrotactile stimuli.

Is there reason to expect to find a tactile AB? Many temporal phenomena, such as saltation, masking, temporal summation, and adaptation, seem to be similar in touch, vision, and audition (Craig, 1982b; Craig \& Evans, 1995; Evans \& Craig, 1991; Geldard, 1982; Gescheider \& Joelson, 1983; Horner, 1995; Kirman, 1986; Rinker \& Craig, 1994; Verrillo, 1992). If any generalization can be made about differences, it is that touch seems to be less discriminative of stimuli presented close in time. For instance, SOAs that do not produce backward masking in vision do so in touch. One complication in studying attention in touch stems from the fact any tactile stimula- 
tion tends to activate a variety of subcutaneous receptors that have different temporal and spatial properties, and the receptors sometimes work independently and at other times interact (Bolanowski, Gescheider, Verrillo, \& Checkosky, 1988; Martin \& Jessell, 1991).

One reason for exploring temporal selection using the $\mathrm{AB}$ paradigm is that, in vision, the $\mathrm{AB}$ has proved to be very robust. It occurs with stimuli that are unquestionably suprathreshold, and it occurs for many different kinds of visual stimuli. We reasoned that if the same kind of temporal selection exists in touch, it should be relatively insensitive to the kinds of receptors triggered and variations in the way the stimuli were presented. Thus, we set out fully expecting that switching between selected stimuli in these dimensions would be subject to the sorts of temporal attentional limitations seen in vision and audition. However, we were only able to find uncontroversial evidence of a tactile $\mathrm{AB}$ under one specific condition: when the two targets were presented in spatially distinct locations. The General Discussion section contains speculations about the reasons for these results.

\section{GENERAL METHOD AND ANALYSES}

The general design was the same for all the experiments described here. Any discrepancies from these general procedures are noted in the Method section for each experiment (see also Table 1 for a summary of the experiments). The participants searched for specified target vibrations in streams of sequentially presented distractor vibrations. Vibrations in each stream were presented at regular temporal intervals or SOAs. Vibrations were presented to the participants' stationary fingertips, and so perception was through cutaneous touch. In various experiments, the intensity, frequency, duration, and location of vibrations were manipulated in various combinations. The participants were told at the start of the experiment how targets differed from nontargets and what they were to report about targets. Before the experiment, the participants were given practice at searching for single targets in streams of nontargets, making the same judgments that were involved in the actual experimental trials that followed. They were given feedback on each practice trial regarding the correctness of their response. For some experiments, there was also an initial set of frequency familiarization trials, in which a single vibration was presented and the participant decided whether the frequency was high or low.

During the experimental trials themselves, two targets were presented in every stream (see Figure 1). The position of the first target varied randomly between the 8th and the 16th position of the stream. T2 could appear anywhere from the position immediately following $\mathrm{T} 1$ (the $\mathrm{T} 1+1$ position) up to 9 positions later (the $\mathrm{T} 1+9$ position). The range of positions tested varied between experiments. T2 appeared equally often in each of the positions tested so that the participants would have no reason to anticipate that $\mathrm{T} 2$ would occur at a particular time after $\mathrm{T} 1$. In the condition of primary interest, the participants reported both targets (i.e., T1 and T2). The participants were instructed that if they could not structure the task so as to report both targets accurately, it was particularly important that they report the first target as accurately as possible. T2 accuracy was analyzed only for trials on which $\mathrm{T} 1$ was correctly reported, because T1 accuracy was the best measure available as to whether the participants had actually attended to T1. In some experiments, feedback was given about the accuracy of each judgment during the experiment; in others, it was not.

Accuracy of T2 report was expected to be lower when T2 appeared soon after $\mathrm{T} 1$ and the participants were to report about both targets. To help discount the possibility that lowered accuracy was due to simple perceptual masking factors, there was another condition in the experimental session in which the participants were presented with the same streams of vibrations but were required to report only T2. If T1 functioned as a straightforward premask for T2, we expected that accuracy of T2 report would increase with the lag between $\mathrm{T} 1$ and $\mathrm{T} 2$, regardless of whether just $\mathrm{T} 2$ or both $\mathrm{T} 1$ and $\mathrm{T} 2$ had to be reported. But if the effect of T2 position on T2 accuracy was due to an $\mathrm{AB}$, we anticipated that it would be seen only when reporting both targets or at least that a smaller position effect would be seen when reporting only $\mathrm{T} 2$ than when reporting both $\mathrm{T} 1$ and T2. (We will return to this point later.) For roughly half the participants in each experiment, the block of trials in which they reported both targets occurred before the block in which they reported only $\mathrm{T} 2$; for the remaining participants, the block in which they re-

Table 1

Methodological Details of the Tactile Experiments

\begin{tabular}{|c|c|c|c|c|c|c|}
\hline Experiment & $\begin{array}{c}\text { SOA } \\
\text { (in msec) } \\
\end{array}$ & $\begin{array}{l}\text { T1-Defining } \\
\text { Feature }\end{array}$ & $\begin{array}{l}\text { T1-Reported } \\
\text { Feature }\end{array}$ & $\begin{array}{l}\text { T2-Defining } \\
\text { Feature }\end{array}$ & $\begin{array}{l}\text { T2-Reported } \\
\text { Feature }\end{array}$ & Distractors \\
\hline 1 & 180 & High intensity & $\begin{array}{l}\text { Frequency } \\
(50 \text { vs. } 350 \mathrm{~Hz})\end{array}$ & Same as $\mathrm{T} 1$ & Same as T1 & $50,200,350 \mathrm{~Hz}$ \\
\hline 2 & 140 & Long duration & $\begin{array}{l}\text { Frequency } \\
(50 \text { vs. } 250 \mathrm{~Hz})\end{array}$ & Same as $\mathrm{T} 1$ & Same as $\mathrm{T} 1$ & $50,150,250 \mathrm{~Hz}$ \\
\hline 3 & 180 & $\begin{array}{l}\text { Frequency } \\
(25 \text { vs. } 400 \mathrm{~Hz})\end{array}$ & $\begin{array}{l}\text { Frequency } \\
(25 \text { vs. } 400 \mathrm{~Hz})\end{array}$ & Low intensity & Presence/absence & $200 \mathrm{~Hz}$ \\
\hline 4 & 170 & Long duration & $\begin{array}{l}\text { Frequency } \\
(50 \text { vs. } 250 \mathrm{~Hz})\end{array}$ & High intensity & Same as $\mathrm{T} 1$ & $50,150,250 \mathrm{~Hz}$ \\
\hline 5 & 160 & $\begin{array}{l}\text { Frequency } \\
(25 \text { vs. } 450 \mathrm{~Hz} \text { or } \\
50 \text { vs. } 350 \mathrm{~Hz})\end{array}$ & $\begin{array}{l}\text { Frequency } \\
(25 \text { vs. } 450 \mathrm{~Hz} \text { or } \\
50 \text { vs. } 350 \mathrm{~Hz})\end{array}$ & $\begin{array}{l}\text { Location } \\
\text { (Index/ring finger) }\end{array}$ & $\begin{array}{l}\text { Location } \\
\text { (Index/ring finger) }\end{array}$ & $\begin{array}{l}250 \mathrm{~Hz} \text { to } \\
\text { middle finger }\end{array}$ \\
\hline 6 & 150 & $\begin{array}{l}\text { Location } \\
\text { (Index/ring finger) }\end{array}$ & $\begin{array}{l}\text { Location } \\
\text { (Index/ring finger) }\end{array}$ & Same as $\mathrm{T} 1$ & Location or absence & Middle finger \\
\hline 7 & 100 & $\begin{array}{l}\text { Location } \\
\text { (Right hand) }\end{array}$ & $\begin{array}{l}\text { Location } \\
\text { (Index finger/thumb) }\end{array}$ & $\begin{array}{l}\text { Location } \\
\text { (Left hand) }\end{array}$ & $\begin{array}{l}\text { Location } \\
\text { (Index finger/thumb) }\end{array}$ & $\begin{array}{l}\text { Only postmasks, } \\
\text { to both fingers on } \\
\text { the hand to which the } \\
\text { target was presented }\end{array}$ \\
\hline
\end{tabular}

Note-In Experiment 7, the SOA was the onset between target and mask. 


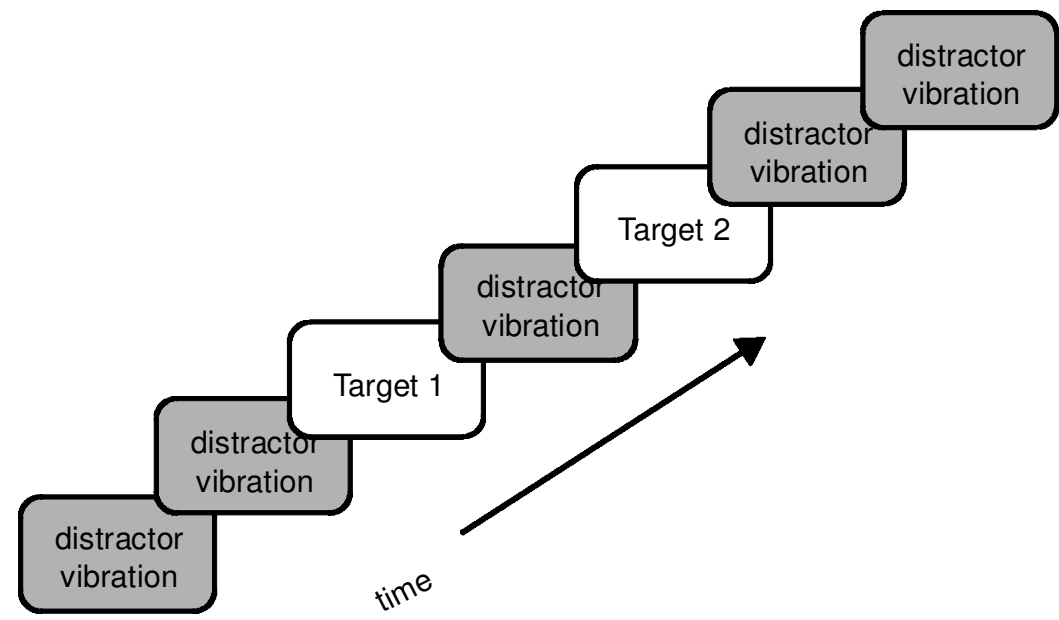

Figure 1. Schematic of the sequence of vibrations in each trial. Although both targets were always presented, in one condition only the second target was reported. The number of vibrations, time between vibrations, and nature of the vibrations were different for each experiment.

ported only $\mathrm{T} 2$ occurred before the block in which they reported both targets. A break was given between the two blocks and periodically within each block. An experimental session typically lasted $90 \mathrm{~min}$.

There were two possible values for T1 and two or three for T2. In each block of trials, an equal number of streams contained each of the $\mathrm{T} 1$ values, each of the $\mathrm{T} 2$ values, and each of the T2 positions. These factors were fully crossed, and the order of trials was randomized.

\section{Participants}

For Experiments 1-6, the participants were recruited from a pool of paid community volunteers and a pool of University of Wales, Bangor, undergraduate psychology students who participated to fulfill an assignment for a course requirement. For Experiment 7, the participants were recruited from a pool of University of Texas at Arlington undergraduate students who participated to fulfill an assignment for a course. With rare exception, the participants participated in a single experiment in this project. When someone participated in more than one experiment, several months elapsed between his or her testing sessions. Detecting vibratory targets proved difficult, so a number of participants who were recruited were excluded from this study due to their poor accuracy. The threshold used was that the participants had to learn the task during practice and that, in the experiment itself, T1 and T2 accuracy had to be significantly different from chance. This resulted in the elimination of 18 participants overall.

\section{Apparatus and Stimuli}

For Experiments 1-6, a Toshiba Equium computer, a Pentiumbased system, was used to control the experiments. For Experiment 7 , a different Pentium-based computer was used. Instructions and feedback were presented visually on the computer monitor. In most experiments, the participants responded using foot pedals. They rested the toes of the right foot on one pedal and the right heel on another pedal during the experiment. Responses consisted of the participants' lifting either their toes or their heels.

The tactors that presented the vibrations were Oticon-A boneconductors that are typically used as hearing aids. The surface area of each tactor was $1.6 \times 2.4 \mathrm{~cm}$. The frequencies used in the experiments ranged from 25 to $450 \mathrm{~Hz}$. The extremes would be registered by different vibrotactile channels, but the intermediate frequencies used (usually 250 or $300 \mathrm{~Hz}$ ) would have been picked up by both. This is an issue, because we wished one frequency to mask others, and vibratory masking is most effective within a vibrotactile channel, not between channels (e.g., Bolanowski et al., 1988).
The tactors made noise as they vibrated. To reduce their noise, they were embedded in foam; in some experiments, medium-grade acoustical foam was used, and in other experiments, a basic baby sponge bought at a supermarket was used. More importantly, the participants listened to pink noise over headphones during the experiment so that they could not hear the tactors. ${ }^{1}$

In most experiments, the participants rested the middle finger of the dominant hand on the tactor, which was embedded in the top of the foam, and the arm rested on a piece of foam to keep the wrist at a comfortable angle. To increase comfort in other experiments, the tactor was embedded in the foam in a way that made it easy to touch when the foam was grasped by the right hand as if it were a computer mouse. This allowed the participants the option of picking up the sponge in order to shift posture during the long experiment (sometimes lasting up to $120 \mathrm{~min}$ ). The participants were instructed that if they shifted the posture of the hand, they should maintain full contact with each tactor on the distal pad of the finger(s) involved. It was recommended that they apply light, rather than full, pressure as they touched the tactors. When the experiment used only one tactor, the distal pad of the middle finger was used (although a few participants were allowed the option of using the index finger due to calluses or scars on the middle finger). When the experiment used three tactors, the distal pads of the index, middle, and ring fingers were used.

A stream consisted of 7-15 vibrations before T1, T1 itself, vibrations up to and including the last possible T2 position, and then 1-3 more vibrations. Thus, if an experiment probed $8 \mathrm{~T} 2$ positions beginning with position $\mathrm{T} 1+1$, there were between 17 and 27 vibrations in the stream. The SOA between elements and the nature of the vibrations that made up targets and distractors will be described for each experiment (see also Table 1). When nontargets were heterogeneous in frequency, the frequencies were selected randomly and independently for each vibration from the set of frequency values. The frequencies were generated as square waves by turning the computer's sound generator on and off at the necessary time intervals and channeling the "sound wave" to the tactors. No attempt was made to ramp onsets or offsets.

\section{Analyses}

All tests of significance in this study were conducted with a criterion of $p<.05$. All accuracies reported are means averaged across values obtained for all participants. In the visual AB literature, an $\mathrm{AB}$ is usually evidenced by the following pattern of accuracies: When both $\mathrm{T} 1$ and $\mathrm{T} 2$ are reported, $\mathrm{T} 2$ report is inaccurate 
when T2 appears soon after T1 but recovers to normal when enough time elapses between the appearance of $\mathrm{T} 1$ and the appearance of $\mathrm{T} 2$. When only T2 is reported, however, this report is always more accurate when $\mathrm{T} 2$ closely follows $\mathrm{T} 1$. In fact, T2 accuracy usually remains relatively constant (and high), regardless of the temporal position of T2 (e.g., Chun, 1997; Duncan, Ward, \& Shapiro, 1994; Maki, Frigen, \& Paulson, 1997; Ward, Duncan, \& Shapiro, 1996).

Because this is the pattern we were looking for, T2 accuracy from each experiment was subjected to an analysis of variance (ANOVA) with two within-subjects factors: task load (both targets reported vs. only $\mathrm{T} 2$ reported) and $\mathrm{T} 2$ position (relative to $\mathrm{T} 1 ; 6-8$ positions probed). Because the data were heteroskedastic, the data were transformed by the arcsine transform before ANOVAs were run. An AB would be evidenced by a significant interaction between task load and position and simple analyses that show that the effect of task load was significant only at relatively early $\mathrm{T} 2$ positions. Because the simple effects analyses are customary, they were done even when the interaction was not significant. We consider them to be analyses chosen a priori. When the $\mathrm{T} 2$ task was a target detection task, the ANOVA was conducted on only those trials in which T2 was present because when $\mathrm{T} 2$ is absent it is not possible to say in what position T2 did not occur, and so the position dependent accuracy estimates cannot be calculated. The likelihood of saying a target was present when it was actually absent will be reported as a measure of the false alarm rate.

\section{EXPERIMENT 1}

In Experiments 1 and 2, vibrations were presented rapidly and serially in a stream. Two vibrations were targets, and the participants reported about both targets in the stream or only about the second target. Both targets were defined by the same feature, and both targets required report of the same feature (the defining feature and the reported feature were the same in one experiment and different in the other). Thus, no task-set switching was involved in these experiments. The temporal distance between the two targets was varied systematically, and the question asked was whether reporting about the first target decreased accuracy in reporting about the second target.

In Experiment 1, targets were more intense (i.e., greater in vibratory amplitude) than nontargets, and the participants reported whether the intense targets to be reported (either both T1 and T2 or only T2, depending on instructions for the block) were high or low in frequency. Nontargets could be of high, low, or intermediate frequency.

\section{Method}

Participants. Seven people participated in this experiment (1 male, 6 females). One was left-handed. Ages ranged from 18 to 47 years (median $=18$ years).

Apparatus and Stimuli. For all participants, the tactor was in contact with the distal pad of the middle finger of the right hand. Distractor frequencies were 50, 200, or $350 \mathrm{~Hz}$. Target frequencies were 50 or $350 \mathrm{~Hz}$. T2 appeared in any of the eight consecutive positions following $\mathrm{T} 1$. The SOA between successive vibrations was $180 \mathrm{msec}$; vibration duration was $120 \mathrm{msec}$, followed by a $60-\mathrm{msec}$ interstimulus interval (ISI) before the next vibration. The tactile stimuli were presented well above threshold, and the intensities used were discriminable as evidenced by the high accuracy of report during practice.

Procedure. Practice started with 60 trials in which a single vibration was presented, and the participants decided which fre- quency it was; practice then concluded with 60 trials of picking out a single intense target in a stream and reporting its frequency. Both blocks of trials in the experiment itself consisted of 224 trials.

\section{Results}

In order to provide information about the reliability of the data in each experiment, Figure $2 \mathrm{~A}$ presents the mean accuracy (averaged across participants) of reporting T2 at each T2 position both when both targets were reported and when only $\mathrm{T} 2$ was reported. There was no systematic difference in accuracy in the two reporting conditions, and, moreover, the effect of $\mathrm{T} 2$ position appeared the same for the two conditions. The ANOVA, with factors of task load and T2 position, confirmed these impressions: Accuracy was significantly affected by $\mathrm{T} 2$ position $[F(7,42)=4.2, p<.01]$, T2 accuracy was not significantly affected by whether or not $\mathrm{T} 1$ was reported $[F(1,6)<1]$, and the interaction between task load and $\mathrm{T} 2$ position did not reach significance $[F(7,42)=1.7]$. The simple effects analyses found $\mathrm{T} 2$ accuracy to be unaffected by whether or not T1 was reported at all T2 positions $[F \mathrm{~s}(1,6)=<1,<1,<1,<1$, $3.3,4.4,4.1$, and $<1$, at consecutive positions]. Thus, there was no conventional evidence of an $\mathrm{AB}$ in this experiment. A possibility that the data represent unconventional evidence of an $A B$ will be discussed after the results of the next experiment are described.

\section{EXPERIMENT 2}

In Experiment 2, we made two modifications to the design of Experiment 1 to address possible reasons why no tactile AB had been demonstrated. First, it has been argued by some researchers that an $\mathrm{AB}$ is more robust as target-distractor discriminability is increased (e.g., Chun \& Potter, 1995). We thought it possible that the failure to demonstrate a tactile $\mathrm{AB}$ in Experiment 1 might have been caused by targets and distractors not being suitably discriminable from each other solely on the basis of their intensity. Therefore, in Experiment 2, targets were slightly longer in duration than nontargets (with no effect on SOA). The participants searched for long vibrations and reported whether these targets (either $\mathrm{T} 1$ and $\mathrm{T} 2$ or only T2) were high or low frequency. Nontargets could be high, low, or intermediate in frequency. Second, we thought it possible that the stimulus presentation rates used in Experiment 1 might simply have been too slow to demonstrate a tactile AB (see Arnell \& Jolicœur, 1999). Therefore, the vibrations were presented at a slightly faster rate in Experiment 2 than in Experiment 1.

\section{Method}

Participants. Seven people participated in this experiment (5 males, 2 females). Two were left-handed. Ages ranged from 18 to 34 years $($ median $=24)$.

Apparatus and Stimuli. For all participants, the tactor was in contact with the distal pad of the middle finger of the dominant hand. Distractor frequencies were 50,150 , or $250 \mathrm{~Hz}$. Target frequencies were 50 or $250 \mathrm{~Hz}$. T2 appeared in any one of the eight consecutive positions following $\mathrm{T} 1$. The SOA between successive vibrations 


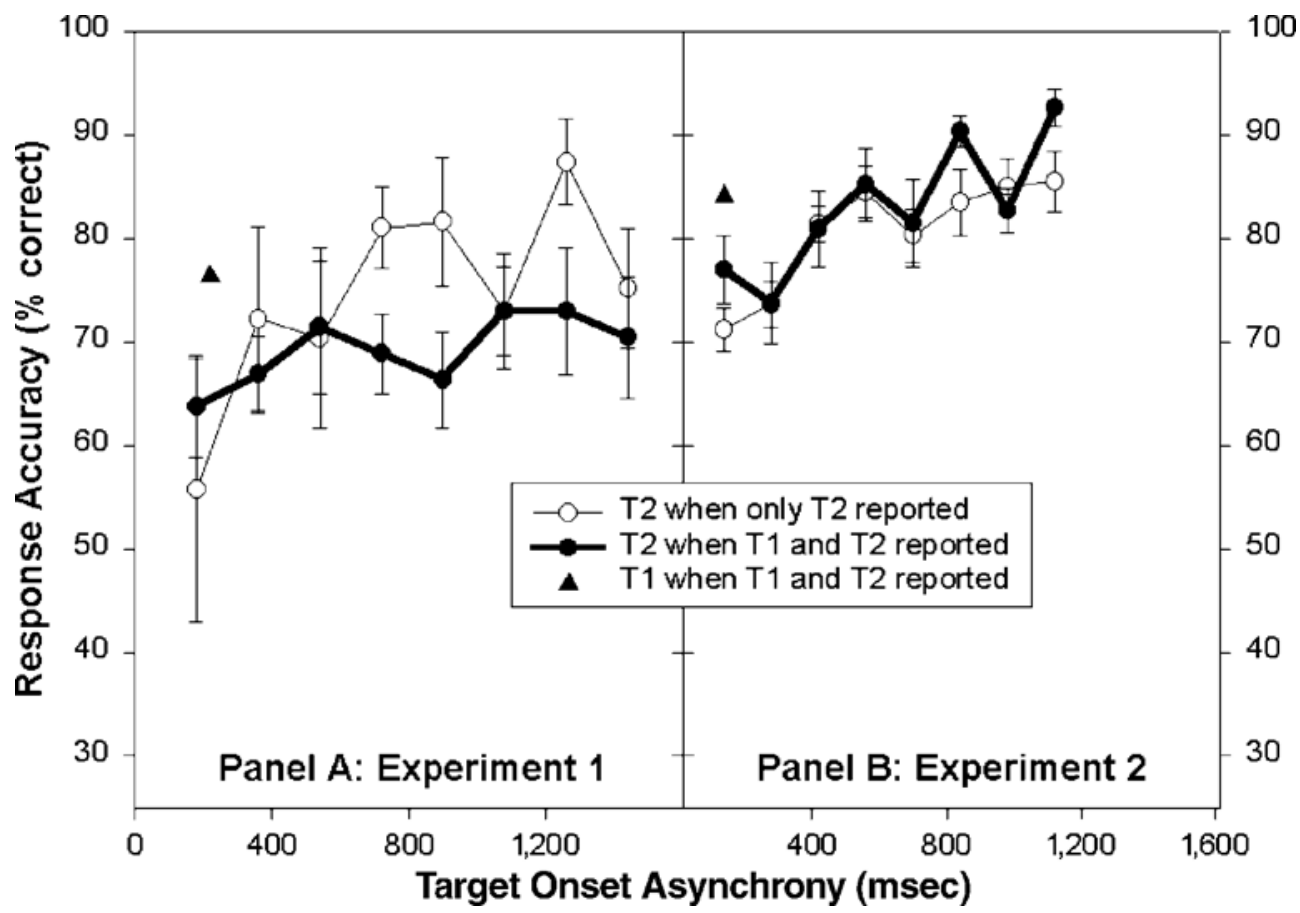

Figure 2. Accuracy of reporting T2 at each T2 temporal position (relative to the T1 position) in Experiment 1 (panel A) and Experiment 2 (panel B) both when only T2 was reported and when both T1 and T2 were reported. This figure also shows the overall accuracy of reporting $\mathrm{T} 1$. In each experiment, the same feature was used to select both targets. Error bars in this and subsequent figures represent the standard error of the mean. For Experiment 1, T1 and T2 were more intense than nontargets, and the participants reported the relative frequency (high or low) of the targets. For Experiment 2, T1 and T2 were longer in duration than nontargets, and the participants reported the relative frequency (high or low) of the targets.

was $140 \mathrm{msec}$. Distractors were presented for $40 \mathrm{msec}$, followed by a 100-msec ISI. Targets were presented for $120 \mathrm{msec}$, followed by a 20-msec ISI.

Procedure. Practice consisted of 40 trials of picking out a single long target in a stream and reporting its frequency. Each of the two experimental blocks consisted of 212 trials.

\section{Results}

Due to time constraints, some participants could not complete all trials in both blocks. Figure $2 \mathrm{~B}$ presents the accuracy of reporting $\mathrm{T} 2$ at each $\mathrm{T} 2$ position both when $\mathrm{T} 1$ and $\mathrm{T} 2$ were reported and when only $\mathrm{T} 2$ was reported. T2 accuracy appeared to be slightly higher on average when both targets were reported than when only $\mathrm{T} 2$ was reported. The effect of T2 position appeared the same for the two conditions. The ANOVA, with factors task load and $\mathrm{T} 2$ position, confirmed these impressions. There was no evidence that $\mathrm{T} 2$ responses were more accurate when both $\mathrm{T} 1$ and $\mathrm{T} 2$ were reported $(83.0 \%)$ than when only T2 was reported $(80.6 \%)[F(1,6)=5.3, p>.05]$. Accuracy was significantly affected by $\mathrm{T} 2$ position $[F(7,42)=10.2, p<.001]$. The interaction between task load and T2 position was not significant $[F(7,42)<1]$. The simple effects analyses revealed higher $\mathrm{T} 2$ accuracy when both targets were reported than when only $\mathrm{T} 2$ was reported for the last T2 position $[F(1,6)=6.1, p<.05]$ and did not reveal any difference at other positions
$\left[F_{\mathrm{s}}(1,6)=2.2,<1,<1,<1,<1,=1.5,<1\right.$, and $=3.2$, at consecutive T2 positions]. Thus, as in Experiment 1, there was no conventional evidence of an $\mathrm{AB}$ in this experiment.

\section{Discussion of Experiments 1 and 2}

Two attempts were made to find a tactile $\mathrm{AB}$, and none was found. Report of T2 was less accurate when it appeared soon after T1, not only when both $\mathrm{T} 1$ and $\mathrm{T} 2$ were reported but also when only T2 was reported. Although it is tempting to interpret the lack of an interaction between task load and T2 position as evidence against an $\mathrm{AB}$ in the tactile modality, such a conclusion may be premature. The effect came about not because T2 accuracy was consistently high in the dual-report condition but rather because the proximity of $\mathrm{T} 2$ to $\mathrm{T} 1 \mathrm{had}$ an effect even when only T2 was reported. Although the effect of $\mathrm{T} 2$ position on accuracy could reflect that $\mathrm{T} 1$ is masking $\mathrm{T} 2$ and not causing an $\mathrm{AB}$, it could also reflect that $\mathrm{T} 1$ is capturing attention even when it is not reported (Arnell \& Jolicœur, 1999).

In the two experiments reported so far, it is quite plausible that the similar nature of $\mathrm{T} 1$ and $\mathrm{T} 2$ led the participants to attend to $\mathrm{T} 1$ even when it was not reported. Because the participants were searching for the second of two targets defined in the same way, they had to be aware 
that the first target had been presented in order to know which was the second one. Although the ability to report whether or not T1 appeared is not equivalent to T1 being attended (Yantis \& Egeth, 1999), it is possible that the task demands of reporting the second of two identically defined targets would result in the first being attended (e.g., see Folk, Remington, \& Johnston, 1992).

Interestingly, very few $\mathrm{AB}$ studies in either vision or audition have used identical defining features for $\mathrm{T} 1$ and T2. Of those that have, many did not include a condition in which only the second target was reported (Breitmeyer, Ehrenstein, Pritchard, Hiscock, \& Crisan, 1999; Chun \& Potter, 1995; Giesbrecht \& Di Lollo, 1998; Mondor, 1998; Potter et al., 1998). In those that did, accuracy was often influenced by T2 position (Chun, 1997; Maki, Couture, Frigen, \& Lien, 1997; Maki, Frigen, \& Paulson, 1997; Potter et al., 1998), and, in one case, no interaction between task load and T2 position was observed (Potter et al., 1998), precisely the pattern observed in Experiments 1 and 2 .

Therefore, it seemed important to examine whether an $\mathrm{AB}$ could be observed if a different target definition was used for T1 than was used for T2. It is also important to examine this issue because Potter et al. (1998) suggested that an $\mathrm{AB}$ will be observed in nonvisual experiments only when processing of both $\mathrm{T} 1$ and $\mathrm{T} 2$ require different task sets. The lack of an AB in Experiments 1 and 2 is completely consistent with their account, since T1 and $\mathrm{T} 2$ used the same task set. The next three experiments to be reported all used different target definitions for the two targets in the tactile stream.

\section{EXPERIMENT 3}

In Experiment 3, nontargets were homogeneous. The first target was higher or lower in frequency than nontargets, and the participants discriminated the relative frequency of $\mathrm{T} 1$ when making a $\mathrm{T} 1$ response. The second target was lower in intensity than nontargets, and the participants simply reported whether or not it was present. As before, in some blocks, the participants reported about both targets, whereas, in other blocks, the participants reported only about the second target. The question was whether reporting about the first target degraded accuracy in reporting about the second.

\section{Method}

Participants. Six people completed this experiment (1 male, 5 females). Two were left-handed. Ages ranged from 18 to 33 years (median $=18$ years).

Apparatus and Stimuli. For all participants, the tactor was in contact with the distal pad of the middle finger of the right hand. Nontargets were $200-\mathrm{Hz}$ vibrations. On the basis of the participants' performance in training, one of two sets of target frequencies was assigned to each participant. For 3 participants, the high frequency was $400 \mathrm{~Hz}$, and the low frequency was $25 \mathrm{~Hz}$. For the remaining 3 participants, the high frequency was $350 \mathrm{~Hz}$, and the low frequency was $50 \mathrm{~Hz}$. The SOA between successive vibrations was $180 \mathrm{msec}$. Vibrations were presented for $130 \mathrm{msec}$, followed by a 50-msec ISI. For the first few participants, T2 appeared in any of the eight consecutive positions following T1. For the remaining participants, to shorten the experiment, T2 appeared in any of the first six consecutive positions following T1.

Procedure. Practice consisted of 64 trials of familiarization with the high and low frequencies, 32 trials of reporting the frequency of a single target in a stream that differed in frequency from nontargets, and 32 trials of reporting whether or not a low-intensity target was present in the stream. In the experiment itself, the block of trials in which only the second target was reported consisted of 212-404 trials, depending on limitations in the time available to run the experiment. The block in which both targets were reported consisted of 144-336 trials. Because of the variation in the number of trials per block, there was not an equal number of trials presented for each cell of the design. A break was given between the two blocks and periodically within each block.

\section{Results}

$\mathrm{T} 2$ positions of $\mathrm{T} 1+7$ and $\mathrm{T} 1+8$ were disregarded for this experiment because only some participants experienced targets in those positions. Figure $3 \mathrm{~A}$ presents the accuracy of reporting $\mathrm{T} 2$ at each $\mathrm{T} 2$ position when both targets were reported and when only $\mathrm{T} 2$ was reported. There was no noticeable difference in accuracy in the two reporting conditions, and the effect of $\mathrm{T} 2$ position appeared the same in both conditions. The ANOVA, with factors task load and T2 position, confirmed these impressions. There was a significant effect of $\mathrm{T} 2$ position $[F(5,25)=4.1, p<.01]$, but there was no significant effect of task load $[F(1,5)<1]$. The interaction between task load and $\mathrm{T} 2$ position reached significance $[F(5,25)=$ $2.7]$. The simple-effects analyses revealed an effect of task load only at the last $\mathrm{T} 2$ position $[F(1,5)=6.7, \mathrm{p}<.05$; at other positions, $F \mathrm{~s}(1,5)=1.2,<1,=1.3,=1.1$, and $=4.3$. At the last $\mathrm{T} 2$ position, reports of $\mathrm{T} 2$ were more accurate when both targets were reported than when only $\mathrm{T} 2$ was reported. Thus, again there was no conventional evidence of a tactile $\mathrm{AB}$ in this experiment.

\section{EXPERIMENT 4}

In Experiment 4, nontargets varied in frequency. The first target was longer in duration than nontargets, and the second target was more intense than nontargets. The participants reported whether the targets (either $\mathrm{T} 1$ and $\mathrm{T} 2$ or only $\mathrm{T} 2$ ) were high or low in frequency.

\section{Method}

Participants. Seven people participated in this experiment (4 males, 3 females). Ages ranged from 20 to 38 years (median $=32$ years).

Apparatus and Stimuli. For all participants, the tactor was in contact with the distal pads of the middle finger of the right hand. Nontargets were $50-, 150-$, or $250-\mathrm{Hz}$ vibrations. Targets were 50 or $250 \mathrm{~Hz}$. The SOA between successive vibrations was $170 \mathrm{msec}$. Nontargets and high-intensity targets were presented for $50 \mathrm{msec}$, followed by a $120-\mathrm{msec}$ ISI. Long targets were presented for $150 \mathrm{msec}$, followed by a 20-msec ISI. T2 appeared in any of the eight consecutive positions following $\mathrm{T} 1$.

Procedure. Practice consisted of 60 trials of deciding whether a single intense target in a stream was high or low frequency and 60 trials of 


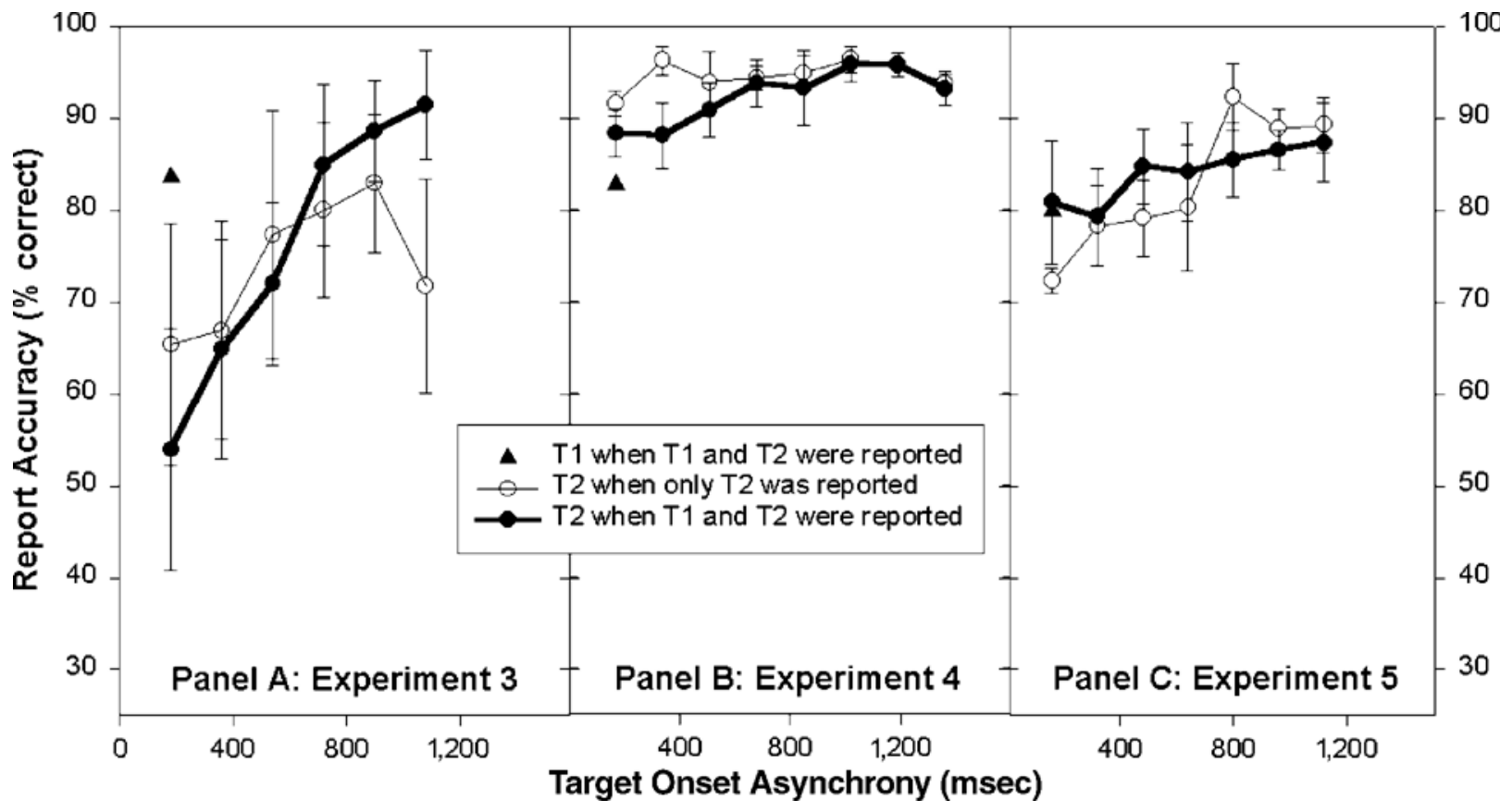

Figure 3. Accuracy of reporting T2 at each T2 temporal position (relative to the T1 position) in Experiment 3 (panel A), Experiment 4 (panel B), and Experiment 5 (panel C) both when only T2 was reported and when both T1 and T2 were reported. This figure also shows the overall accuracy of reporting T1. For Experiment 3, T1 was different in frequency from nontargets, and the participants reported its frequency (high or low). $\mathbf{T} 2$, if present, was lower in intensity than nontargets, and the participants reported its presence or absence. For Experiment 4, T1 was longer in duration than nontargets, and T2 was higher in intensity than nontargets, and the participants reported the relative frequency (high or low) of the targets. For Experiment 5 , T1 was different in frequency from nontargets, and the participants reported its relative frequency. $T 2$ was to the left or the right of nontargets, and the participants reported its location.

deciding whether a single long target in a stream was high or low frequency. For 2 participants, each block in the experiment itself consisted of 212 trials; for the remainder, each block consisted of 224 trials.

\section{Results}

Figure 3B presents the accuracy of reporting $\mathrm{T} 2$ at each $\mathrm{T} 2$ position both when both targets were reported and when only $\mathrm{T} 2$ was reported. It appears that at early T2 positions accuracy was lower when both targets were reported. The ANOVA gave some support to this. T2 position had a significant effect $[F(7,42)=3.0, p<.025]$, but both task load and the interaction between task load and $\mathrm{T} 2$ position were nonsignificant $[F(1,6)=1.2$, and $F(7,42)=1.1$, respectively]. However, the simple-effects tests revealed a significant effect of task load at position $\mathrm{T} 1+2$ (time between targets, $340 \mathrm{msec}$ ) $[F(1,6)=7.3$, $p<.05$ ], but no significant difference at any other T2 position $[F \mathrm{~s}(1,6)<1]$. In this experiment, the simpleeffects results give a small amount of evidence of an AB, but not the conventional pattern in which the two main factors interact significantly.

\section{EXPERIMENT 5}

Frequency is not perceptually independent of intensity or duration (Cohen \& Kirman, 1986; Fucci, Petrosino, Harris, \& McMath, 1986; Gescheider, Berryhill, Verrillo,
\& Bolanowski, 1999; Gescheider \& Joelson, 1983; Taylor, 1977; Verrillo, 1992; Verrillo, Fraioli, \& Smith, 1969), and so in Experiments 3 and 4, a criterion set up to select targets defined by one of the features would necessarily also select targets defined by the other. To avoid this problem, in Experiment 5, the first target was on the middle finger and was higher or lower in frequency than nontargets, and the participants reported the relative frequency, whereas the second target was presented to the left or right of nontargets, and the participants reported its location.

This was the first experiment in which $\mathrm{T} 2$ was presented at a location at which no stimulus had yet been presented during the trial. If the significant effect of T2 position in the previous experiments was caused by $\mathrm{T} 1$ masking the subsequently presented $\mathrm{T} 2$ (or by the stream as a whole masking T2), this manipulation should reduce such masking (Horner, 1995).

\section{Method}

Participants. Five people completed this experiment ( 2 males, 3 females).

Apparatus and Stimuli. For all participants, the tactor was in contact with the distal pads of the index, middle, and ring fingers of the right hand. The participants responded with the left hand on the keyboard. Nontargets were $250-\mathrm{Hz}$ vibrations. One of two sets of T1 target frequencies was assigned to each participant. For 2 participants, the high frequency was $350 \mathrm{~Hz}$, and the low frequency was $50 \mathrm{~Hz}$. For the remaining 3 participants, the high frequency was 
$450 \mathrm{~Hz}$, and the low frequency was $25 \mathrm{~Hz}$. The participants reported what they felt by pressing " 1 " for a high-frequency target and " 2 " for a low-frequency target. T2 was presented either to the index finger (considered the left) or to the ring finger (considered the right). T2 was $250 \mathrm{~Hz}$, like nontargets, and was always followed by a lowfrequency vibration $(25$ or $50 \mathrm{~Hz}$, according to the frequencies chosen for $\mathrm{T} 1$ for that participant) presented to both the index finger and the ring finger. The participants indicated a left target by pressing " 1 " and a right target by pressing " 2 ." The SOA between successive vibrations was $160 \mathrm{msec}$. Vibrations were presented for $110 \mathrm{msec}$, followed by a $50-\mathrm{msec}$ ISI. T2 appeared in any of the seven consecutive positions in the stream following T1.

Procedure. Practice consisted of 60 trials of familiarization with high and low frequencies (discriminating the frequency of a single vibration), 48 trials of deciding whether a single target in a stream was presented on the left or the right, and 48 trials of deciding whether a single target in a stream was higher or lower in frequency than nontargets. The two experimental blocks consisted of 196 trials each.

\section{Results}

Figure $3 \mathrm{C}$ presents the accuracy of reporting $\mathrm{T} 2$ at each $\mathrm{T} 2$ position both when $\mathrm{T} 1$ and $\mathrm{T} 2$ were reported and when only T2 was reported. Whether or not T1 was reported did not noticeably affect T2 accuracy, and the effect of T2 position appeared the same for the two conditions. The ANOVA, with factors task load and $\mathrm{T} 2$ position, confirmed these impressions. There was a significant effect of $\mathrm{T} 2$ position $[F(6,24)=3.2, p<.025]$, but there was no effect of task load $[F(1,4)<1]$ nor of the interaction between task load and $\mathrm{T} 2$ position $[F(6,24)<1]$. The simple-effects analyses revealed no effect of task load at any $\mathrm{T} 2$ position $[F \mathrm{~s}(1,4)<1]$. Thus, there was no conventional evidence of a tactile $A B$ in this experiment.

It was argued earlier that one reason an $\mathrm{AB}$ was not obtained might have been that T1 masked T2. In this experiment, despite efforts to reduce premasking on T2, by presenting $\mathrm{T} 2$ on a different finger than any stimuli that had been presented earlier in the stream, there was still a position effect and, again, no tactile AB. Forward masking is seen when the mask is presented to one finger and the target is presented to another (Craig \& Evans, 1995), although at a reduced level. No reduction of the effect of $\mathrm{T} 2$ position was observed in this experiment.

\section{Discussion of Experiments 1-5}

In Experiment 4, the effect of task load was significant at position $\mathrm{T} 1+2$. This is tenuous evidence for an $\mathrm{AB}$. No other experiments produced any evidence at all of an $\mathrm{AB}$, by a conventional definition. This may have been due in part to low power in the experiments, because it was not possible to run as many participants in each experiment as we would have liked. To increase power, an ANOVA was run including data from all 36 participants who were involved in Experiments 1-5. The ANOVA included experiment (5 levels) as a between-subjects factor and task load (2 levels) and T2 position (6 levels) as within-subjects factors. In this ANOVA, the effects of experiment and $\mathrm{T} 2$ position were significant $[F(4,27)=$ $3.4, p<.025$, and $F(5,135)=15.5, p<.001$, respec- tively]. No other effects were significant, and so this analysis again did not produce a typical $A B$ pattern.

In Experiments 3-5, a different selection criterion was used for T1 and T2. In addition, the participants in Experiments 3 and 5 reported different attributes/features of the two targets as well. To push the statistical tests a bit further, another ANOVA was run including data from only Experiments 3-5. This ANOVA, too, did not reveal a pattern of statistical significance indicating an AB. Only T2 position significantly affected the results $[F(5,75)=8.4$, $p<.001]$.

\section{EXPERIMENT 6}

It seems surprising that touch would show no $\mathrm{AB}$, given that tactile responses are sensitive to other attentional effects (Bradshaw et al., 1992; Butter et al., 1989; Craig \& Rollman, 1999; Hsiao, Johnson, Twonbly, \& DiCarlo, 1996; Hsiao et al., 1993; Lloyd, Bolanowski, Howard, \& McGlone, 1999; Mattingley, Driver, Beschin, \& Robertson, 1997; Posner, 1978, p. 207; Post \& Chapman, 1991; Sathian \& Burton, 1991; Spence et al., 1998; Spence, Pavani, \& Driver, 2000; Whang et al., 1991; Zompa \& Chapman, 1995). However, we know of only one study that has investigated cuing of nonspatial tactile features (Burton et al., 1999), and half of the participants in that study showed no attentional effect. Because there is robust evidence in the literature that location judgments engage attention when dealing with tactile stimuli (e.g., Spence \& McGlone, 2001; Spence, Pavani, \& Driver, 2000), we switched to asking the participants to judge the location of targets presented in streams that were not all at the same location. Nontargets in the stream were presented to the middle finger. Targets were on the left (index finger) or right (ring finger) of nontargets. Masks were presented immediately after targets to both the index finger and the ring finger.

In Experiment 6, a location judgment was used for both $\mathrm{T} 1$ and $\mathrm{T} 2$ to maximize our potential for finding an $\mathrm{AB}$. Using location judgments also addressed another problem. Given that the stimuli being presented were vibrations, at the outset of this project it seemed reasonable to vary duration, intensity, and frequency of the vibrations when selecting target parameters. It turns out, however, that these three features are not independent of one another (Cohen \& Kirman, 1986; Gescheider et al., 1999; Gescheider \& Joelson, 1983; Taylor, 1977; Verrillo, 1992; Verrillo et al., 1969), and an attentional set to distinctiveness in any one of these dimensions may have picked up on distinctiveness in the other dimensions (Folk et al., 1992). Thus, when set to attend to the T2-defining feature, the T1-defining feature may have been inadvertently attended because it partly triggered the attentional set. Using location judgments in Experiment 6 circumvented the interdependence of the other features of the vibrations.

Pilot testing suggested that participants might adopt a strategy of dealing with $\mathrm{T} 2 \mathrm{~s}$ that they did not detect as hav- 
ing been presented at the same location as T1s. To counteract this strategy, in Experiment 6, T2 was absent on a third of the trials. Thus, the participants reported whether T1 was on the left or the right and whether T2 was on the left or the right or, alternatively, absent. T1 was always present.

\section{Method}

Participants. Fifteen people participated in this experiment ( 3 males, 12 females). All were right-handed. Ages ranged from 18 to 32 years $($ median $=22$ years).

Apparatus and Stimuli. For all participants, tactors were in contact with the distal pads of the index, middle, and ring fingers of the right hand. Responses were made on the keyboard with the left hand. If a target appeared on the left, the number " 1 " on the keyboard was pressed. If a target appeared on the right, the number " 3 " on the keyboard was pressed. If T2 was absent, the number " 2 " on the keyboard was pressed. T2 could appear at any of the eight consecutive positions following T1's mask (positions T1 2 through $\mathrm{T} 1+9$, according to the labels adopted earlier).

Most elements in the tactile stream were nontargets that were presented to the middle finger. Each target was presented to the index finger or the ring finger. A mask followed each target (or an absent T2), consisting of a low-frequency vibration $(50 \mathrm{~Hz})$ presented to both the index finger and the ring finger. When a target or mask was presented to the index finger or the ring finger, no nontarget was presented concurrently to the middle finger. All vibrations, whether targets, masks, or nontargets, were presented for $100 \mathrm{msec}$, followed by a 50-msec ISI, and so the SOA between successive vibrations was $150 \mathrm{msec}$. All vibrations were $350 \mathrm{~Hz}$.

Procedure. Practice consisted of 72 trials of deciding whether a single target was presented on the left, on the right, or not at all. For half the participants, both blocks in the experiment itself consisted of 336 trials. For the remaining participants, both blocks consisted of 192 trials.

\section{Results}

The $\mathrm{T} 2$ responses in this experiment can be analyzed either in terms of correct localization or correct detection. Because the target was sometimes absent, it was possible to measure false alarm rates by treating responses of "left" and "right" as "present" responses. This was done in order to exclude the participants who were close to chance at detecting T2. Seven of the 15 participants were excluded because their false alarm rates were greater than $40 \%$. $^{2}$ False alarm rates for the remaining 8 participants ranged from $1.5 \%$ to $36.7 \%$ (median $=24.7 \%$ ). The presence of the mask, even when $\mathrm{T} 2$ was absent, made detecting the absence of T2 quite difficult. ${ }^{3}$

The results of this experiment were more suggestive of an AB. There was a large effect of SOA in both the singlereport condition and the dual-report condition, but the effect of SOA was less marked in the single-report condition (see Figure 4). An ANOVA on the accuracy of localization responses, with the factors task load and T2 position, confirmed these impressions. It revealed a significant effect of lag $[F(7,49)=24.2, p<.001]$ but no significant effect of task load or the interaction of task load with lag $[F(1,7)=2.5$, and $F(7,49)<1$, respectively]. However, the a priori simple-effects tests demonstrated that, at the first T2 position (position T1 +2 ), task load had a significant effect $[F(1,7)=15.2, p<.01]$, whereas, at the other
$\mathrm{T} 2$ positions, it did not $\left[F_{\mathrm{s}}(1,7)=1.0,<1,=1.6,<1\right.$, $=1.8,<1$, and $=1.1$, consecutively $]$.

\section{Discussion}

As in Experiment 4, we found tenuous evidence for an AB: an effect of task load at the T1 +2 position (300msec SOA). Because the effect occurred when T1 and T2 appeared at locations different from the distractor stream, it is possible that the observed outcome resulted from a transient spatial cuing effect. Under such an account, attention was drawn to T1, and T2 was reported less accurately when it appeared in another target location than $\mathrm{T} 1$. This would produce an AB pattern, averaging across locations, if the spatial effect was very strong. If this is an accurate account, $\mathrm{T} 2$ detection ought to be mediated by the relative locations of T1 and T2. In other words, accuracy should be high at reporting $\mathrm{T} 2$ when it appears at the same location as T1, and accuracy should be low if it appears at the opposite location, particularly at early $\mathrm{T} 2$ positions. In fact, a post hoc ANOVA of T2 accuracy, with factors of task load (report both T1 and T2 or only T2), $\mathrm{T} 2$ position, and relative spatial locations of targets (two targets in either the same location or different locations) revealed a significant effect of T2 location $[F(1,7)=9.7$, $p<.025]$ (same side accuracy $=77.1 \%$; different side accuracy $=83.9 \%$ ) but no significant interactions involving T2 location. It appears, then, that the spatial focus of

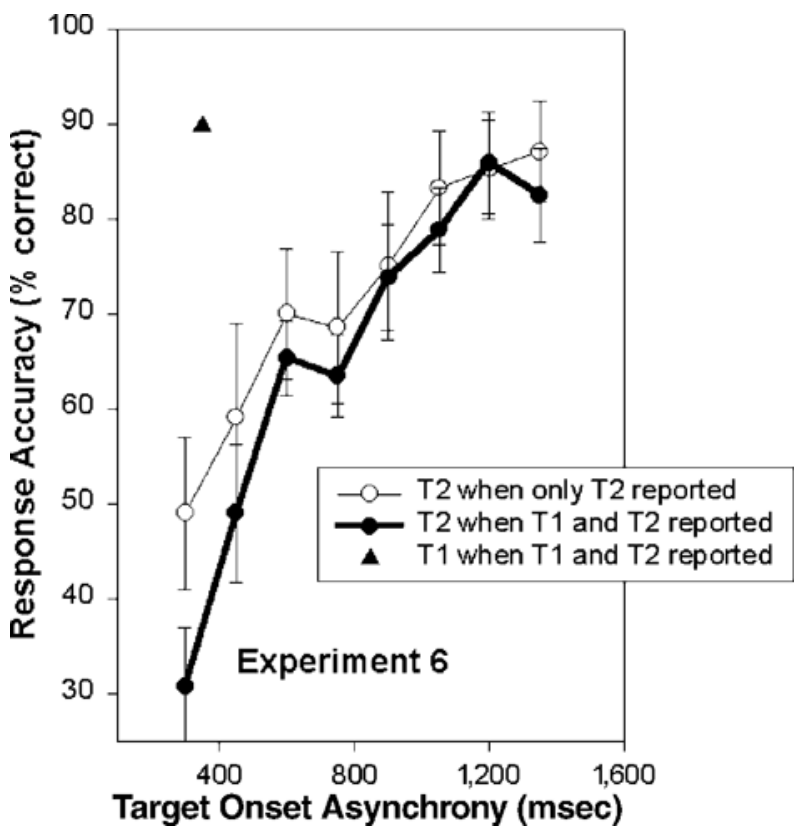

Figure 4. Accuracy of reporting the presence of $\mathrm{T} 2$ at each $\mathrm{T} 2$ temporal position (relative to the T1 position) in Experiment 6 both when only $\mathrm{T} 2$ was reported and when both $\mathrm{T} 1$ and $\mathrm{T} 2$ were reported. The figure also shows the overall accuracy of reporting T1. T1 was to the left or the right of nontargets. T2 was to the left or the right of nontargets or was absent. 
attention affected overall accuracy but did not cause the AB-like results seen in this experiment.

\section{EXPERIMENT 7}

Because the evidence for an $\mathrm{AB}$ was weak in Experiment 6 , a final experiment was run to replicate the results using a design to further minimize masking and increase statistical power. In Experiment 7, T1 was presented to the right hand, and T2 was presented to the left hand. The targets were a single vibration either to the thumb or the index finger, and the participants reported the location (finger or thumb) of the target. Each target was followed by a shorter, higher frequency vibration (the mask) presented to both the thumb and the forefinger of the same hand. Other than masks following T1 and T2, no other stimuli were presented. Such an impoverished stream has been shown to produce an $\mathrm{AB}$ in visual displays (e.g., Duncan et al., 1994; Soto-Faraco et al., in press). Because targets were easier to detect in this design, it was possible to reduce the SOA between target and mask and between first and second targets, thus presenting more trials in which $\mathrm{T} 2$ position was within the time period expected to produce an $\mathrm{AB}$.

\section{Method}

Participants. Sixteen people from the University of Texas at Arlington participated in this experiment (5 males, 11 females). All were right-handed. Ages ranged from 18 to 37 years $($ median $=$ 20 years).

Apparatus and Stimuli. For all participants, tactors were in contact with the distal pads of the index fingers and thumbs of both the left and right hands. Because there was a chance that, when only reporting vibrations to the left hand, the participants might lighten their grasp on tactors presented to the right hand, they rested each hand on its back, approximately shoulder-width apart. Tactors were taped to the thumb and the index finger of each hand, which made it impossible for the participants to voluntarily change the force with which they contacted the tactors to which they were attending (cf. Spence, Shore, \& Klein, 2001). The participants responded by raising toes if the target was on the index finger and raising the heel if the target was on the thumb. Target onset asynchronies were 200, $300,400,500,600,700,800$, and $900 \mathrm{msec}$. Targets were $450-\mathrm{Hz}$ vibrations presented for $80 \mathrm{msec}$, and masks were $100-\mathrm{Hz}$ vibrations presented for $60 \mathrm{msec}$.

Procedure. Practice consisted of 20 trials of unmasked targets to the right hand, 20 trials of unmasked targets to the left hand, 20 trials of masked targets to the right hand, and 20 trials of masked targets to the left hand, presented in that order. In the experiment, there were between 8 and 10 blocks of 24 trials in which only targets to the left hand were reported, and there were between 8 and 10 blocks of 24 trials in which targets on both hands were reported.

\section{Results}

One participant's data were not analyzed because of errors in how the experiment was run. A clear AB that lasted at least $400 \mathrm{msec}$ was observed in this experiment. There was a large effect of SOA in both the single-report condition and the dual-report condition, but the effect of SOA was less marked in the single-report condition (see Figure 5). An ANOVA on the accuracy of localization re-

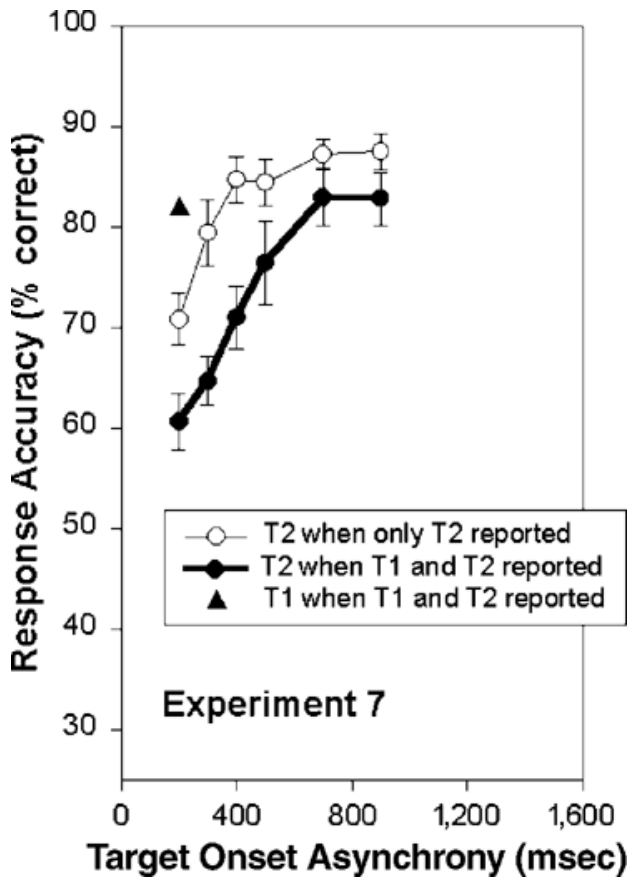

Figure 5. Accuracy of reporting the location of $\mathrm{T} 2$ at each $\mathrm{T} 2$ temporal position (relative to the $T 1$ position) in Experiment 7 both when only $\mathrm{T} 2$ was reported and when both $\mathrm{T} 1$ and $\mathrm{T} 2$ were reported. The figure also shows the overall accuracy of reporting T1. T1 was on the right hand. T2 was on the left hand.

sponses, with factors of task load and $\mathrm{T} 2$ position, confirmed these impressions. It revealed a significant effect of lag and task load and a significant interaction between them $[F(5,70)=44.4, p<.001 ; F(1,14)=10.9, p<$ .01 ; and $F(5,70)=3.4, p<.01$, respectively]. The a priori simple-effects tests demonstrated that, at the first three T2 positions (200, 300, and $400 \mathrm{msec})$, task load had a significant effect $[F \mathrm{~s}(1,14)=11.2,18.7$, and 17.5, respectively, $p \mathrm{~s}<.01, .001, .001]$, whereas, at the other $\mathrm{T} 2$ positions, it did not $\left[F_{\mathrm{s}}(1,14)=2.7,1.3\right.$, and 1.8 , respectively].

\section{GENERAL DISCUSSION}

In the experiments reported here, we sought to demonstrate whether an $\mathrm{AB}$ would occur when participants were attending to vibrotactile targets. In Experiments 1-5, we examined various combinations of targets defined by duration, frequency, location, and amplitude. The overall pattern of results in these experiments revealed an effect only of SOA. However, in Experiment 4, the data suggest that a small AB might have occurred when targets appeared approximately $340 \mathrm{msec}$ apart. In Experiments 6 and 7, targets were defined by their location, and the participants made localization judgments. In Experiment 6, the results revealed a dual-target cost when the second target appeared approximately $300 \mathrm{msec}$ after the first target; however, again the evidence was tenuous. In Experiment 7 , 
in which the targets were on different hands, an AB clearly occurred. In Experiments 6 and 7, we believe that the results were due to temporal shifting of attention rather than spatial shifting of attention. If the results were simply due to spatial cuing, then the $\mathrm{AB}$ would only be evident when T1 and T2 were in different locations. But the effect was no different when $\mathrm{T} 1$ and $\mathrm{T} 2$ were in the same location than when they were in different locations.

According to convention, we would attribute the results of the earlier experiments (results showing an effect of intertarget interval on $\mathrm{T} 2$ accuracy regardless of whether or not $\mathrm{T} 1$ was reported) to perceptual masking of $\mathrm{T} 2$ by T1. However, even though tactile masking can be quite strong, tactile stimuli, like visual stimuli, seem to be more susceptible to backward masking than to forward masking (e.g., Craig, 1976, 1982a, 1982b; Kirman, 1986; Verrillo \& Gescheider, 1979; Weisenberger \& Craig, 1982). So it is unlikely that masking would play as strong a role as it did in these experiments.

Another nonattentional factor that could have produced the pattern of results of Experiments 1-5 is the brief duration of tactile short-term memory. Tactile shortterm memory has less capacity than visual short-term memory (Bliss, Crane, Mansfield, \& Townsend, 1966). In the first six experiments reported here, $\mathrm{T} 2$ position was partially confounded with the number of elements following it: When T2 appeared soon after T1, more elements followed it than when it appeared in later positions. This has not proved to be an important factor in obtaining visual $\mathrm{ABs}$; however, if tactile short-term memory were particularly susceptible to decay or interference, it might be an explanation for why $\mathrm{T} 2$ report was usually poor when T2 appeared soon after T1. But T1 accuracy was usually better than $\mathrm{T} 2$ accuracy, even though the time between $\mathrm{T} 1$ and the end of the trial was longer than the time between $\mathrm{T} 2$ and the end of the trial. Thus, short-term memory failures cannot account for the pattern of results that obtained.

Despite the strong likelihood that nonattentionalfactors played a role in the earlier experiments, there are also reasons to believe that even the results of the earlier experiments demonstrated an AB. In particular, the results were entirely consistent with the possibility that the first target triggered an $\mathrm{AB}$ even when the first target was not reported. Such an outcome could arise if the participants inadvertently attended to $\mathrm{T} 1$ in that condition, in spite of instructions to the contrary. Although participants are able to ignore $\mathrm{T} 1 \mathrm{under}$ typical visual target conditions, other T1-T2 conditions (e.g., tactile-visual; cf. Soto-Faraco et al., in press) have revealed SOA effects on single-target trials similar to those witnessed here. Interpretation of such an effect is difficult, and it is simply not possible to rule out that an $\mathrm{AB}$ is occurring. One reason to believe that the participants attended to $\mathrm{T} 1$ even when not reporting it in the early experiments is that, even when $\mathrm{T} 1$ and $\mathrm{T} 2$ were defined by nominally different attributes, the attributes were perceptually nonindependent. Duration, intensity, and frequency of vibrations are not independent(Cohen \& Kirman, 1986; Gescheider et al., 1999; Gescheider \& Joelson, 1983; Taylor, 1977; Verrillo, 1992; Verrillo et al., 1969); thus, an attentional set to distinctiveness in any one of these dimensions may have picked up on distinctiveness in the other dimensions (Folk et al., 1992). Therefore, when set to attend to the T2-defining feature, the T1defining feature may have been inadvertently attended because it partly triggered the attentional set. But perhaps the most compelling reason to believe that $\mathrm{T} 1$ may have been attended in these experiments is that, in Experiment 7, in which masking of $\mathrm{T} 2$ by $\mathrm{T} 1$ was minimized and in which $\mathrm{T} 2$ position was not confounded with the number of nontargets presented, the temporal proximity of $\mathrm{T} 2$ to $\mathrm{T} 1$ still affected response accuracy when only $\mathrm{T} 2$ was reported $[F(5,70)=20.7, p<.001]$.

Although the possibility that $\mathrm{T} 1$ captured attention in all the experiments, despite instructions to the contrary, and thus resulted in an $\mathrm{AB}$ in all the experiments is consistent with the results, such a conclusion would leave us with the question of why T1 drew attention less in Experiments 6 and 7. Our tentative answer is that the spatial separation of $\mathrm{T} 1$ from $\mathrm{T} 2$ in the latter experiments allowed the participants to spatially focus attention in a way that reduced the likelihood of T1 capturing attention. Spatial focus of attention has been shown to reduce the impact of attention-drawing nontargets in vision (Yantis \& Johnston, 1990). Our results suggest that, in touch, spatial focus works similarly but is less effective than in vision. It could also turn out to be important that the judgment concerned the location of the targets. In other words, it may be not simply the spatial separation of the targets but also the fact that the participants were judging the location of the targets that produced the result. In other paradigms, it has proved easier to find attentional effects when participants are making localization judgments than when making other types of judgments (see McDonald \& Ward, 1999; Spence \& Driver, 1994; Spence, Pavani, \& Driver, 2000).

Consider a distinction that has been found between vision and audition. In vision, attention can be focused on locations, features, objects, and so almost any kind of visual targets will produce an AB. In audition, attention to particular frequency ranges is demonstrated easily, but attention to spatial locations seems to depend on location being critical in the judgment to be made (McDonald \& Ward, 1999; Spence \& Driver, 1994). Nobody has tried to demonstrate an $\mathrm{AB}$ in audition using location judgments, but there have been a few demonstrations of auditory ABs using frequency judgments (e.g., Goddard et al., 1997; Mondor, 1998).

In trying to explain why location has a role in vision but not in audition, theorists have turned to the organization of various sensory cortices. The attentional primacy of frequency over location in audition has been attributed to the tonotopic organization of the cochlea in the human brain (McDonald \& Ward, 1999; Spence \& Driver, 1994). Auditory location is not available at the cochlea and must be 
computed centrally, by specialized location-sensitiveneurons. Perhaps this explanation, which has been applied only to the role of location in attention, applies to the role of all features in attention. Accordingly, in order for attention to be focused on a feature, that feature would have to play a role in the organization of the primary sensory cortex. Primary visual cortex is organized spatiotopically, but it also shows columnar regularity in terms of features other than space (Hubel \& Wiesel, 1977), and visual attention can select those features. Touch is like vision in that (1) receptors register the location of stimulation immediately, albeit not always very precisely (Marshall, Woolsey, \& Bard, 1941; Penfield \& Rasmussen, 1950) and (2) spatial representation is influenced by more than simply the distance between activated receptors (Driver \& Grossenbacher, 1996). Many aspects of spatial processing seem similar in the visual and tactile modalities (e.g., Marks \& Armstrong, 1996). But the columns in primary somatosensory cortex represent distinct classes of receptors, rather than representing the subtle vibrotactile feature variations used in the present experiments (Mountcastle, 1957). Perhaps experiments using features other than localization that are more separable in terms of the receptors that register them will reveal an $\mathrm{AB}$.

We set out to explore an $\mathrm{AB}$ in the tactile domain to see whether current explanations of ABs account for attentional effects in all senses. On the basis of auditory and visual data, Potter et al. (1998) proposed that, in nonvisual streams, an $\mathrm{AB}$ would be found only when the definitions of $\mathrm{T} 1$ and $\mathrm{T} 2$ differed enough to require set switching. The results reported here do not fit this model, regardless of how one might interpret them. If our account - that all our experiments revealed an $\mathrm{AB}$ - is accepted, then the model needs to be expanded to explain why touch works like vision. If, on the other hand, our results are interpreted as showing that only Experiments 6 and 7 showed an $A B$, then an $\mathrm{AB}$ was found only in some (but not all) instances in which the target definition was the same for T1 and T2. The present series of experiments provide new input for the current debate on the existence of divided attention deficits within and between modalities.

\section{REFERENCES}

Arnell, K. M., \& Duncan, J. (1998, November). Substantial interference between response selection and stimulus encoding. Paper presented at the annual meeting of the Psychonomic Society, Dallas.

ARnell, K. M., \& Jolicceur, P. (1999). The attentional blink across stimulus modalities: Evidence for central processing limitations. Journal of Experimental Psychology: Human Perception \& Performance, 25, 630-648.

Bliss, J. C., Crane, H. D., Mansfield, P. K., \& Townsend, J. T. (1966). Information available in brief tactile presentations. Perception \& Psychophysics, 1, 273-283.

Bolanowski, S. J., Gescheider, G. A., Verrillo, R. T., \& Checkosky, C. M. (1988). Four channels mediate the mechanical aspects of touch. Journal of the Acoustical Society of America, 84, 1680-1694.

Bradshaw, J. L., Howard, M. J., Pierson, J. M., Phillips, J., \& BradSHAW, J. A. (1992). Effects of expectancy and attention in vibrotactile choice reaction time tasks. Quarterly Journal of Experimental Psychology, 44A, 509-528.

Breitmeyer, B. G., Ehrenstein, A., Pritchard, K., Hiscock, M., \&
Crisan, J. (1999). The roles of location specificity and masking mechanisms in the attentional blink. Perception \& Psychophysics, 61, 798-809.

Broadbent, D. E., \& Broadbent, M. H. P. (1987). From detection to identification: Response to multiple targets in rapid serial visual presentation. Perception \& Psychophysics, 42, 105-113.

Burton, H., Abend, N. S., MacLeod, A. M. K., Sinclair, R. J., SnYDER, A. Z, \& RAIChLE, M. E. (1999). Tactile attention tasks enhance activation in somatosensory regions of parietal cortex: A positron emission tomography study. Cerebral Cortex, 9, 662-674.

Butter, C. M., Buchtel, H. A., \& Santucci, R. (1989). Spatial attentional shifts: Further evidence for the role of polysensory mechanisms using visual and tactile stimuli. Neuropsychologia, 27, 1231-1240.

Chun, M. M. (1997). Temporal binding errors are redistributed by the attentional blink. Perception \& Psychophysics, 59, 1191-1199.

Chun, M. M., \& Potter, M. (1995). A two-stage model for multiple target detection in rapid serial visual presentation. Journal of Experimental Psychology: Human Perception \& Performance, 21, 109-127.

Cohen, B., \& Kirman, J. H. (1986). Vibrotactile frequency discrimination at short durations. Journal of General Psychology, 113, 179-186.

CraIG, J. C. (1976). Vibrotactile letter recognition: The effects of a masking stimulus. Perception \& Psychophysics, 20, 317-326.

Craig, J. C. (1982a). Temporal integration of vibrotactile patterns. Perception \& Psychophysics, 32, 219-229.

Craig, J. C. (1982b). Vibrotactile masking: A comparison of energy and pattern maskers. Perception \& Psychophysics, 31, 523-529.

Craig, J. C., \& Evans, P. M. (1995). Tactile selective attention and temporal masking. Perception \& Psychophysics, 57, 511-518.

Craig, J. C., \& Rollman, G. B. (1999). Somesthesis. Annual Review of Psychology, 50, 305-331.

Driver, J., \& Grossenbacher, P. G. (1996). Multimodal spatial constraints on tactile selective attention. In T. Inui \& J. L. McClelland (Eds.), Attention and performance XVI (pp. 209-236). Cambridge, MA: MIT Press.

Duncan, J., Martens, S., \& WARD, R. (1997). Restricted attentional capacity within but not between sensory modalities. Nature, 387, 808-810.

Duncan, J., Ward, R., \& Shapiro, K. (1994). Direct measurement of attentional dwell time in human vision. Nature, 369, 313-315.

Evans, P. M., \& Craig, J. C. (1991). Tactile attention and the perception of moving tactile stimuli. Perception \& Psychophysics, 49, 355-364.

Folk, C. L., Remington, R. W., \& Johnston, J. C. (1992). Involuntary covert orienting is contingent on attentional control settings. Journal of Experimental Psychology: Human Perception \& Performance, 18, 1030-1044.

Fucci, D., Petrosino, L., Harris, D., \& McMath, E. (1986). Stimulus duration effects on vibrotactile magnitude estimation for the tongue and hand. Bulletin of the Psychonomic Society, 24, 193-196.

Geldard, F. A. (1982). Saltation in somesthesis. Psychological Bulletin, 92, 136-175.

Gescheider, G. A., Berryhill, M. E., Verrillo, R. T., \& BolanowSKI, S. J. (1999). Vibrotactile temporal summation: Probability summation or neural integration? Somatosensory \& Motor Research, 16, 229-242.

Gescheider, G. A., \& Joelson, J. M. (1983). Vibrotactile temporal summation for threshold and suprathreshold levels of stimulation. Perception \& Psychophysics, 33, 156-162.

Giesbrecht, B., \& Di Lollo, V. (1998). Beyond the attentional blink: Visual masking by object substitution. Journal of Experimental Psychology: Human Perception \& Performance, 24, 1454-1466.

Goddard, K. M., IsAaK, M. I., \& Slawinski, E. B. (1997). The auditory attentional blink: Inhibition revisited. Journal of the Acoustical Society of America, 101, 3125.

Goddard, K. M., IsaAK, M. I., \& Slawinski, E. B. (1998). The auditory attentional blink in a congenitally blind population. In P. K. Kuhl \& L. A. Crum (Eds.), Proceedings of the 16th International Congress on Acoustics and the 135th Meeting of the Acoustical Society of America (Vol. 3, pp. 2333-2334). New York: Acoustical Society of America.

HoRnER, D. T. (1995). The effect of location on the discrimination of spatial vibrotactile patterns. Perception \& Psychophysics, 57, 463-474.

Hitao, S. S., Johnson, K. O., Twonbly, A., \& DiCarlo, J. (1996). Form processing and attention effects in the somatosensory system. In 
O. Franzen, R. Johansson, \& L. Terenius (Eds.), Somesthesis and the neurobiology of the somatosensory cortex (pp. 229-247). Basel: Birkhauser.

HsiaO, S. S., O'Shaughnessy, D. M., \& Johnson, K. O. (1993). Effects of selective attention on spatial form processing in monkey primary and secondary somatosensory cortex. Journal of Neurophysiology, 70, 444-447.

Hubel, D. H., \& Wiesel, T. N. (1977). Functional architecture of macaque monkey visual cortex (Ferrier Lecture). Proceedings of the Royal Society of London: Series B, 198, 1-59.

KIRMAN, J. H. (1986). Vibrotactile frequency recognition: Forward and backward masking effects. Journal of General Psychology, 113, 147 158.

LedERMAN, S. J., \& KLATZKY, R. L. (1997). Relative availability of surface and object properties during early haptic processing. Journal of Experimental Psychology: Human Perception \& Performance, 23, 1680-1707.

Lloyd, D. M., Bolanowski, S. J., JR., Howard, L., \& McGlone, F. (1999). Mechanisms of attention in touch. Somatosensory \& Motor Research, 16, 3-10.

Maki, W. S., Couture, T., Frigen, K., \& Lien, D. (1997). Sources of the attentional blink during rapid serial visual presentation: Perceptual interference and retrieval competition. Journal of Experimental Psychology: Human Perception \& Performance, 23, 1393-1411.

Maki, W. S., Frigen, K., \& PAulson, K. (1997). Associative priming by targets and distractors during rapid serial visual presentation: Does word meaning survive the attentional blink? Journal of Experimental Psychology: Human Perception \& Performance, 23, 1014-1034.

Marks, L. E., \& Armstrong, L. (1996). Haptic and visual representations of space. In T. Inui \& J. L. McClelland (Eds.), Attention and performance XVI (pp. 263-287). Cambridge, MA: MIT Press.

MarKs, L. E., \& Wheeler, M. E. (1998). Attention and the detectability of weak taste stimuli. Chemical Senses, 23, 19-29.

Marshall, W. H., Woolsey, C. N., \& BARD, P. (1941). Observations on cortical somatic sensory mechanisms of cat and monkey. Journal of Neurophysiology, 4, 1-24

MARTIN, J. H., \& JESSELl, T. M. (1991). Modality coding in the somatic sensory system. In E. R. Kandel, J. H. Schwartz, \& T. M. Jessell (Eds.), Principles of neural science (pp. 341-352). New York: Elsevier.

Mattingley, J. B., Driver, J., Beschin, N., \& Robertson, I. H. (1997). Attentional competition between modalities: Extinction between touch and vision after right hemisphere damage. Neuropsychologia, 35, 867 880 .

McDonald, J. J., \& WARD, L. M. (1999). Spatial relevance determines facilitatory and inhibitory effects of auditory covert spatial orienting. Journal of Experimental Psychology: Human Perception \& Performance, 25, 1234-1252.

Mondor, T. A. (1998). A transient processing deficit following selection of an auditory target. Psychonomic Bulletin \& Review, 5, 305-311.

MountCAST Le, V. B. (1957). Modality and topographic properties of single neurons of cat's somatic sensory cortex. Journal of Neurophysiology, 20, 408-434.

Penfield, W., \& Rasmussen, T. (1950). The cerebral cortex of man: A clinical study of localization of function. New York: Macmillan.

Posner, M. I. (1978). Chronometric explorations of mind. Hillsdale, NJ: Erlbaum.

Post, L. J., \& Chapman, C. E. (1991). The effects of cross-modal manipulations of attention on the detection of vibrotactile stimuli in humans. Somatosensory \& Motor Research, 8, 149-157.

Potter, M. C., Chun, M. M., Banks, B. S., \& Muckenhoupt, M. (1998). Two attentional deficits in serial target search: The visual attentional blink and an amodal task-switch def icit. Journal of Experimental Psychology: Learning, Memory, \& Cognition, 24, 979-992.

Raymond, J., Shapiro, K., \& ARnell, K. M. (1992). Temporary suppression of visual processing in an RSVP task: An attentional blink? Journal of Experimental Psychology: Human Perception \& Performance, 18, 849-860.

Rinker, M. A., \& Craig, J. C. (1994). The effects of spatial orientation on the perception of moving tactile stimuli. Perception \& Psychophysics, 56, 356-362.
Sathian, K., \& Burton, H. (1991). The role of spatially selective attention in the tactile perception of texture. Perception \& Psychophysics, 50, 237-248.

Shapiro, K. L., Arnell, K. M., \& Raymond, J. E (1997). The attentional blink: A view on attention and a glimpse on consciousness. Trends in Cognitive Sciences, 1, 291-296.

Shulman, H. G. (1994, November). The attention blink in RSVP and $R A P$. Poster presented at the annual meeting of the Psychonomic Society, St. Louis.

Shulman, H. G., \& Hsieh, V. (1995, November). The attentionalblink in mixed modality streams. Paper presented at the annual meeting of the Psychonomic Society, Los Angeles.

Soto-Faraco,S., \& Spence, C. (2002). Modality-specific auditory and visual temporal processing deficits. Quarterly Journal of Experimental Psychology, 55A, 23-40.

Soto-Faraco, S., Spence, C., Fairbank, K., Kingstone, A., HillSTROM, A. P., \& ShapIro, K. (in press). A cross-modal attentional blink between vision and touch. Psychonomic Bulletin \& Review.

SPENCE, C. J., \& Driver, J. (1994). Covert spatial orienting in audition: Exogenous and endogenous mechanisms facilitate sound localization. Journal of Experimental Psychology: Human Perception \& Performance, 20, 555-574.

Spence, C., Kettenmann, B., Kobal, G., \& McGlone, F. P. (2000). Selective attention to the chemosensory modality. Perception \& Psychophysics, 62, 1265-1271.

SPENCE, C., \& McGlone, F. P. (2001). Reflexive orienting of tactile attention. Experimental Brain Research, 141, 324-330.

Spence, C., Nicholls, M. E. R., Gillespie, N., \& Driver, J. (1998). Cross-modal links in exogenous covert spatial orienting between touch, audition, and vision. Perception \& Psychophysics, 60, 544-557.

Spence, C., Pavani, F., \& Driver, J. (2000). Crossmodal links between vision and touch in covert endogenous spatial attention. Journal of Experimental Psychology: Human Perception \& Performance, 26, 1298-1319.

Spence, C., Shore, D. I., \& Klein, R. M. (2001). Multimodal prior entry. Journal of Experimental Psychology: General, 130, 799-832.

TAY LOR, B. (1977). Dimensional interactions in vibrotactile information processing. Perception \& Psychophysics, 21, 477-481.

Verrillo, R. T. (1992). Vibration sensation in humans. Music Perception, 9, 281-302.

Verrillo, R. T., Fraioli, A. J., \& Smith, R. L. (1969). Sensation magnitude of vibrotactile stimuli. Perception \& Psychophysics, 6, 366-372.

Verrillo, R. T., \& Gescheider, G. A. (1979). Backward enhancement and suppression of vibrotactile sensation. Sensory Processes, 3, 249260.

Ward, R, Duncan, J., \& Shapiro, K. (1996). The slow time-course of visual attention. Cognitive Psychology, 30, 79-109.

Weichselgartner,E., \& Sperling, G. (1987). Dynamics of automatic and controlled visual attention. Science, 238, 778-780.

Weisenberger, J. M., \& Craig, J. C. (1982). A tactile metacontrast effect. Perception \& Psychophysics, 31, 530-536.

Whang, K. C., Burton, H., \& Shulman, G. L. (1991). Selective attention in vibrotactile tasks: Detecting the presence and absence of amplitude change. Perception \& Psychophysics, 50, 157-165.

YANTIS, S., \& EgEth, H. E. (1999). On the distinction between visual salience and stimulus-driven attentional capture. Journal of Experimental Psychology: Human Perception \& Performance, 25, 661-676.

YANTIS, S., \& Johnston, J. C. (1990). On the locus of visual selection: Evidence from focused attention tasks. Journal of Experimental Psychology: Human Perception \& Performance, 16, 135-149.

Zompa, I. C., \& Chapman, C. E. (1995). Effects of cross-modal manipulations of attention on the ability of human subjects to discriminate changes in texture. Somatosensory \& Motor Research, 12, 87-102.

\section{NOTES}

1. The experimenters could not hear the operation of the vibrotactile stimulators when they were wearing headphones, and when the participants said that they thought that they could, they were asked to take their hand off of the tactor for a few sample streams to see if a response could 
be made based on hearing auditory cues alone. The participants and the experimenters were both satisfied that the perception of sound was due to their tactile contact with the vibrotactile stimulator. Note though that we cannot rule out the possibility that soundwaves were conducted through the body from fingertips to ears.

2. All data included in the analyses of Experiment 2 - the other experiment involving present/absent judgments - were from participants who met this false alarm criterion.

3. False alarm rates are usually used as measures of the prevalence of guessing for stimuli that were presented but missed by the participant. A blink would result in more misses of $\mathrm{T} 2$ in the condition in which both
$\mathrm{T} 1$ and $\mathrm{T} 2$ are reported. Therefore, a high false alarm rate could make report appear more accurate in dual report than it really is, thus potentially making an $\mathrm{AB}$ look shallower than it really is. It would have been ideal to correct accuracies for the high false alarm rates. But we believe that there should be more guessing in early $\mathrm{T} 2$ positions than in late $\mathrm{T} 2$ positions, and there was no way to figure false alarm rates at each $\mathrm{T} 2$ position; an absent target has no position.

(Manuscript received June 6, 2000;

revision accepted for publication November 19, 2001.) 